\title{
Optimization of Distributed Generation Integrated into Micro Grids Considering the Correlation of DGs
}

\author{
Zeng Pin-zhuo, Wang Ke-you, Li Guo-jie and Jiang Xiu-chen \\ Key Laboratory of Control of Power Transmission and Transformation, Ministry \\ of Education (Department of Electrical Engineering, Shanghai Jiao Tong \\ University), Shanghai 200240, China \\ zengpinzhuo@163.com
}

\begin{abstract}
Optimal allocation of distributed generations (DGs) integrated into micro grids can significantly improve the stability and benefit the economy of micro grid operation. However, optimal micro grid planning is a kind of multi-dimensional and non-linear optimization problem. In this study, a multi-objective model is established by adopting the objective function which minimizes network loss, electricity price and operation cost; an improved particle swarm optimization (IPSO) algorithm with better optimizing performance is proposed by improving the initializing method and parameter control as well as average minimum and mutation factor are introduced. The proposed IPSO algorithm is then applied to a 29-node micro grid network structure. The comparison between different optimization schemes demonstrates the significance of optimal placement of DGs in micro grids. And it is also clear that the IPSO algorithm proposed in this study can effectively solve such problems.
\end{abstract}

Keywords: Micro grid; distributed generation; multi-objective optimization; improved particle swarm optimization algorithm; mutation operator

\section{Introduction}

Energy shortage and gradual maturity of micro grid technology has promoted rapid development of distributed generation technology. The power system is undergoing great impact caused by distributed power generation technology based on micro grid. The distributed generation (DG) in the form of micro grids accesses to large power grids for grid-connected operation ${ }^{[1]}$, and completes each other with traditional large power grids. It will improve economy and reliability of system operation and be the inexorable trend of development of smart grid. It has become a hot spot for researches on electric power system. Distributed power generation normally includes a large quantity of new energy generation which is with strong undulation and uncertainty. Connection of a large amount of DG will result in change of micro grid flow and voltage, while unreasonable DG connected location and capacity may cause numerous adverse impacts [2-3]. Therefore, in the process of developing smart grid and studying micro grid technology, how to optimize the access locations and capacities of various types of DGs safely, reliably and economically has vital research significance.

The first problem in the optimal planning of DGs is the location selection and capacity determination of DG. Numerous scholars in the world have carried out various researches on it. In Literature [4], a multi-objective model of DG is established in smart grid and an improved adaptive genetic algorithm is adopted to optimize placed location and capacity of DG. In Literature [5], a method for DG planning in distributed grid expansion planning is proposed and genetic algorithm optimization is applied to calculate location and capacity of DG. In Literature [6], a model which targets at minimum loss of network loss 
is established to analyze the change of distribution network loss before and after placement of DG. And on this basis, improved particle swarm optimization (IPSO) algorithm which adopts simulated annealing (SA) is put forward for optimization of DG planning. In Literature [7], a new evolutionary algorithm and genetic algorithm is proposed to combine with SA algorithm for solution of placed location of DG with minimum network loss. In Literature [8], the ant colony optimization (ACO) algorithm is applied to determine the optimal planning of DGs in distribution systems and the objective function of model has considered various costs and network loss cost during DG operation.

Based on consideration of correlation of distributed generation placement and importance of load, a multi-objective model is established in this study by adopting the objective function which minimizes network loss and comprehensive operation cost. In the solving process, an improved particle swarm optimization (IPSO) algorithm is adopted and a 29-node micro grid network structure analysis is carried out to prove the effectiveness of the IPSO algorithm.

\section{Optimal DG Planning Based on Micro Grid}

\subsection{Correlation and Location Selection Principles of Connection of Distributed Generation}

In micro grid planning, we should consider that DGs can give full play to the features of low cost, low energy consumption and high power quality to improve the economy and environment in this region firstly. However, in case of unreasonable planning of location and capacity of DGs and arbitrary placement and installation, the cost and power loss will increase and power quality of system will decline.

Based on importance and sensitivity, the loads in micro grids can be classified into sensitive loads, adjustable loads and interruptible loads. As the facility construction in cities and towns has formed, the placed location of DGs will be impacted by geographical environment, load types and user demands ${ }^{[9-10]}$. Distribution of primary energy is also closely related to land form, height and climate. The environment characteristics of covered areas are endowed with strong similarity by the networking mode of micro grid based on distribution system and system scale and distribution of primary energy has correlativity. Primary energy distribution of distributed generation is closely related to the natural conditions like climate, land form and height. For example, wind energy change is strongly random and asynchronous motor is mainly adopted as the wind driven generator. After connecting, the micro grid requires a large amount of reactive powers, resulting in voltage variance and impacting voltage stability of the whole micro grid to a certain degree which is related with placed location and capacity of DG.

Determination of connection types of distributed generation mainly bases on national energy policies and requirements of power market. Applicable DG type is selected according to district resource advantages and characters of DGs. For instance, wind power generation is adopted for the regions with strong winds; photovoltaic power generation is employed for the regions with high sunlight intensity. The following table lists basic characteristics of typical DG types for selection reference of DGs.

Table 1. Basic Characteristics of Typical DG

\begin{tabular}{ccccccc}
\hline & $\begin{array}{c}\text { Generat } \\
\text { ing } \\
\text { efficien } \\
\text { cy/\% }\end{array}$ & $\begin{array}{c}\text { power } \\
\text { density } \\
(\mathrm{kW} / \mathrm{m} 2)\end{array}$ & $\begin{array}{c}\text { Investme } \\
\mathrm{nt} \\
\operatorname{cost}(\mathrm{d} / \mathrm{k} \\
\mathrm{W})\end{array}$ & $\begin{array}{c}\text { Operating } \\
\text { and } \\
\text { maintenance } \\
\text { fee }(\mathrm{d} / \mathrm{kWh})\end{array}$ & $\begin{array}{c}\text { Grid } \\
\text { price }(\mathrm{d} / \mathrm{k} \\
\mathrm{Wh})\end{array}$ & $\begin{array}{c}\text { Capacit } \\
\text { y range } \\
(\mathrm{kW})\end{array}$ \\
\hline $\begin{array}{c}\text { Micro gas } \\
\text { turbine }\end{array}$ & 30 & 59 & 122 & 0.006 & 0.07 & $30-200$ \\
\hline
\end{tabular}




\begin{tabular}{ccccccc}
\hline $\begin{array}{c}\text { photovoltaic } \\
\text { generation }\end{array}$ & 11 & 0.02 & 1100 & 0.0025 & 0.2 & $5-200$ \\
\hline $\begin{array}{c}\text { wind power } \\
\text { generation }\end{array}$ & 25 & 0.01 & 168 & 0.01 & 0.03 & $5-1000$ \\
\hline fuel cell & 50 & 2 & 500 & 0.0017 & 0.07 & $5-5000$ \\
\hline
\end{tabular}

At the same time, from the perspective of power market, installation of distributed generation at important load nodes within the micro grid can effectively improve the power distribution reliability. With regard to unimportant loads, it is feasible to install distributed generation on the large area of vacant lands possessed by the user or enterprise factories which respond to national call of low carbon. Thus the nodes applicable for installation of distributed generation can be classified into:

(1) Wind turbine generation system or photovoltaic power generation system can be installed in the places with regional environment and geographical location applicable for installation of distributed generation, such as gym, park, and etc;

(2) Distributed generation can be installed and connected according to user demand in order to obtain high-quality power;

(3) Distributed generation is applied for the special users, such as hospital, communication facilities and government agencies, can guarantee normal power supply to facilitate disaster assistance and failure removal in the emergent events, such as disaster and failure.

At present, researches on the contract model of different micro grid loads in power market environment are still rare and it is hard to predict the grid price of these loads. Thus, no differentiation of electricity price of all loads is considered in the optimization model in this study.

\subsection{Calculation of Micro Grid Load Flow}

Correct load flow calculation of micro grids is the basis for optimization of distributed generation placement in micro grids. As the features which include radiation, small wire diameter, numerous subcircuits and large ratio of $\mathrm{R}$ and $\mathrm{X}$ of grid structure of micro grids are similar to that of distribution network, load flow calculation can be improved on the basis of load flow calculation of distribution network. In this paper, forward-back substitution algorithm is adopted. This algorithm is the most widely applied currently and has excellent linear convergence capacity [11-12]. The model adopted by distributed generation in the micro grid can be simplified as PV node or PQ node. This paper will set it as PQ node with constant power factor. DG is generally installed at the place close to a load center, so we can assume that DG is directly installed on the load node.

\subsection{Placing Particular Emphasis on Economic Multi-Objective Optimization Model}

In order to realize maximized benefits of micro grid, the placed location and capacity of distributed generation in micro grids is optimized in this paper. In accordance with network structure and load growth at various load nodes in the grid, economic optimizing operation is realized on the premise that all constraint conditions in grid have been satisfied. The planning period of micro grids in this paper is 10 years and it is assumed that all load nodes have been available at the initial planning stage. Multi-objective optimization model which takes operation cost and network loss into consideration is adopted and the complete objective function is as follows:

$C_{\text {min }}=C_{D G}+C_{E N}+C_{L}$ 
Solve the objective components in Formula (1):

(1) comprehensive costs for operation of DG:

$$
\begin{aligned}
& C_{D G}=T_{\max } \sum_{i=1}^{m} \eta_{i} S_{D G i} C_{e D G i} \\
& =\sum_{i=1}^{m}\left(T_{\max } \eta_{i} S_{D G i}\left\lfloor\frac{r(r+1)^{n_{D G}}}{(r+1)^{n_{D G}}-1} \frac{C_{D G i}}{T_{\max }}\right\rfloor+C_{D M i}\right)
\end{aligned}
$$

In Formula (2), $T_{\max }$ is the annual maximum load hours (h); $m$ is the introduced total amount of distributed generations; $\eta_{i}$ is the power factor; $S_{D G i}$ is the capacity of No. $i$ distributed generation; $C_{e D G i}$ is the electricity cost of DG with unit capacity; $r$ is the annual interest rate; $n_{D G}$ is payback period; $C_{D G i}$ is the construction cost of DG with unit capacity; $C_{D M i}$ is the maintenance cost.

(2) Power purchase cost of micro grid:

$$
C_{E N}=C_{e} \tau_{j \max }\left(\sum_{j=1}^{n} P_{L O A D j}-\sum_{i=1}^{m} P_{D G i}\right)
$$

In Formula (3), when $\sum_{j=1}^{n} P_{L O A D j}>\sum_{i=1}^{m} P_{D G i}$, the powers supplied by distributed generation fail to meet the power demand of all loads in micro grids, so the remained loads should purchase power from large grid and it is positive, $C_{E N}$ stands for expenditure; when $\sum_{j=1}^{n} P_{L O A D j}<\sum_{i=1}^{m} P_{D G i}$, there is power for selling to large grids after meeting the power demand in micro grids and it is negative, $C_{E N}$ stands for income.

(3) Network loss cost:

$C_{L}=C_{e} \tau_{j \max } \sum_{j=1}^{n} R_{j} \frac{P_{j}^{2}}{\left(U_{N} \eta_{j}\right)^{2}}$

In Formula (4), $n$ is the number of wires; $C_{e}$ is the unit electricity price (Yuan/kWh); $\tau_{j \max }$ is the annual maximum load hours (h) of subcircuit $\mathrm{j} ; P_{j}$ is the active powers flowing through subcircuit $\mathrm{j} ; R_{j}$ is resistance of subcircuit $\mathrm{j} ; \eta_{j}$ is the load power factor of subcircuit $\mathbf{j} ; U_{N}$ is the nominal voltage of circuit.

\subsection{Constraint Conditions}

Load flow equation:

$\left\{\begin{array}{l}P_{s i}-U_{i} \sum_{j \in i} U_{j}\left(G_{i j} \cos \theta_{i j}+B_{i j} \sin \theta_{i j}\right)=0 \\ Q_{s i}-U_{i} \sum_{j \in i} U_{j}\left(G_{i j} \sin \theta_{i j}+B_{i j} \cos \theta_{i j}\right)=0\end{array}\right.$

Constraint of node voltage:

$U_{i \min }<U_{i}<U_{i \max }$

Capacity limit of each distributed generation:

$P_{k L O A D}<P_{k D G}<P_{D G \max }$ 
In Formula (7), $P_{k L O A D}$ is the load at node $k$; upper limit of capacity of distributed generation.

Permeability $\lambda$ of micro grid to large grid should satisfy:

$\lambda_{\min }<\lambda<\lambda_{\max }$

In Formula (8), permeability of micro grid is $\lambda=\frac{\sum P_{D G}-\sum P_{L O A D}}{P_{S}}, \sum P_{D G}$ is the gross capability of DG, $\sum P_{\angle O A D}$ is the all load powers in micro grid, total power of large grid.

Meanwhile, when optimizing renewable energy sources integration like wind power and PV power, wind power generator and photovoltaic power system have requirements for installation locations and working environment. Thus, considering correlation of DGs placed location, it is necessary to consider the limit of the placed locations of wind power generator and PV system.

\section{Particle Swarm Algorithm and its Improvement}

\subsection{Basic Particle Swarm Algorithm}

Particle Swarm Optimization (PSO) algorithm is an intelligent optimization method based on global intelligent search of swarm intelligence by simulating the migratory and swarm behaviors of bird flock during foraging. PSO algorithm is easy to realize, with strong global search ability, so it is applicable for solution of non-linear and nondifferentiable complicated optimization problems. Mathematical description of PSO algorithm: search the optimal solutions of $\mathrm{m}$ random particles in D-dimensional space. After iteration for $\mathrm{t}$ times, location of particle $i$ is $x_{i}{ }^{t}=\left(x_{i 1}{ }^{t}, x_{i 2}{ }^{t}, \ldots, x_{i D}{ }^{t}\right)$, speed is $v_{i}{ }^{t}=\left(v_{i 1}{ }^{t}, v_{i 2}{ }^{t}, \ldots, v_{i D}{ }^{t}\right)$; in each iteration process, the particle update itself by following individual extreme value $p_{i}{ }^{t}$ searched by the particle and global extreme value $p_{g}{ }^{\prime}$ searched by the whole swarm. Each particle can update its speed and location in solving space according to following formulas ${ }^{[13]}$ :

$v_{i}^{t+1}=\omega v_{i}{ }^{t}+c_{1} r_{1}\left(p_{i}{ }^{t}-x_{i}{ }^{t}\right)+c_{2} r_{2}\left(p_{g}{ }^{t}-x_{i}^{t}\right)$

$x_{i}{ }^{(t+1)}=x_{i}{ }^{t}+v_{i}{ }^{(t+1)}$

In Formula (9), $\mathrm{t}$ is iteration frequency, $x_{i}{ }^{t}$ and $v_{i}{ }^{t}$ is the position vector and tvelocity vector at No.t iteration; $\omega$ is the inertia weight; $c_{1} 、 c_{2}$ is the learning factor; $r_{1} 、 r_{2}$ is the random number between $[0,1]$

\subsection{Improved Particle Swarm Algorithm}

To strength the convergence ability of particle swarm algorithm, it is suggested to avoid local optimum and improve search capability. This paper improves the basic particle swarm algorithm in the following aspects:

1) Improvement of initialized method of PSO algorithm

Currently, the normally applied particle position initialization method is generated randomly, thus when the particle dimension increases, algorithm convergence will significantly decline. In the present paper, simplex method is adopted to initiate the algorithm. Firstly, n peaks are generated randomly and then the objective function value of peak is calculated. The peaks with maximum and minimum function values will be taken as the initial particles for simplex method iteration. IF new maximum and minimum function values appear, then the corresponding peaks will be new particles until required 
sufficient particles are obtained. The particles treated by complex method initialization can fully present the "peak valley" feature of function in the feasible space, thus simplex method can be regarded as the ideal initialization method for particle swarm algorithm.

2) Introduction of control factors for dynamic adjustment of inertia weight

Linearly decreasing inertia weight for standard particle swarm algorithm will place the algorithm in local extreme value field. This paper introduces a method with control factor to dynamically adjust the inertia weight and the mathematical expression is ${ }^{[14]}$ :

$\omega_{t}=\omega_{\text {end }}+\left(\omega_{\text {start }}-\omega_{\text {end }}\right) \exp \left(-k \times\left(\frac{t}{t_{\max }}\right)^{2}\right)$

In Formula (11), $k$ is the control factor for dynamic adjustment of inertia weight with time; $k$ is selected according to differences of objective function to obtain a nonlinearly varied inertia weight coefficient so as to effectively improve the convergence ability of algorithm.

3) Introduction of average extreme value item

In standard particle swarm algorithm, each particle only utilizes its individual extreme value and global extreme value to update its own velocity and place. At the later stage of iteration, the algorithm may gather nearby the local extreme value point for searching, but neglect the second-best solution which may be obtained by other particles. Thus, in the present paper, an average extreme value item is added to the velocity updating formula ${ }^{[15]}$ to regard the average information of whole swarm as an important reference basis for decision of particle velocity.

Let the vector of average individual extreme value at No.t iteration be:

$p a^{t}=\left(p a_{1}^{t}, p a_{2}^{t}, \ldots, p a_{D}^{t}\right)$

Therein, $p a_{i}^{t}=\left(p a_{1}^{t}+p a_{2}^{t}+\ldots+p a_{M}^{t}\right) / M$.

Improved particle velocity update formula is:

$v_{i d}^{t+1}=\omega_{t} v_{i d}^{t}+c_{1} r_{1}\left(p_{i}^{t}-x_{i}^{t}\right)+c_{2} r_{2}\left(p_{g}^{t}-x_{i}^{t}\right)+c_{3} r_{3}\left(p a_{i}^{t}-x_{i}^{t}\right)$

In Formula (13), $r_{3}$ is even-distributed random number between $(0,1) ; \quad c_{3}$ is the learning factor.

In the iterative process of algorithm, particle's individual extreme value, global extreme value and average extreme value gradually approach into a same point, leading to convergence of algorithm to optimal solution so as to effectively solve the problem of search stagnation caused by weakened searching ability at later stage.

4) Introduction of mutation operator

In order to effectively give up local optimal solution and find out the global optimal solution at later stage of convergence, mutation operator is introduced in this paper. After each iteration, a certain amount of particles will be selected based on mutation rate for mutation processing and globally optimal particles are selected every time. In this paper, the mutation rate is 0.3 after multiple experiments, namely $P_{m}=0.3$, selected particle $i$ will mutate with strategy of stochastic disturbance. The following operators will be adopted:

$$
x_{i d}^{t}=\operatorname{random}\left\{0,1, \ldots, x_{D}^{t}\right\}
$$

In Formula (14), after mutation, individual extreme value $p_{i}^{t}$ and global extreme value $p_{g}^{t}$ of particle will be updated. If after mutation of optimal individual particle, particle fitness is $F_{t}\left(p_{g}^{t}\right)<F_{t}\left(p_{g}^{\prime}\right)$, then $p_{g}^{t}=p_{g}^{\prime}$ is the optimal solution before mutation. This mutation strategy can effectively avoid local optimization due to rapid convergence and strengthen the global searching ability. 


\section{DG optimization Solving Process based on IPSO Algorithm}

\subsection{Improved Particle Swarm Algorithm}

(1) Input initial network parameters, constraint conditions and algorithm parameters etc.

(2) Adopt simplex method to initialize the swarm to generate velocity and place of initial particle.

(3) Set current place of each particle as individual extreme value and the minimum value in the swarm is set as global extreme value.

(4) Call forward-back substitution load follow calculation program to calculate the fitness of each particle and upgrade individual extreme value and global extreme value according to the fitness.

(5) Introduce mutation operators to conduct mutation processing on the particles.

(6) Introduce mutation operators to conduct mutation processing on the particles.

(7) Continually upgrade individual extreme value and global extreme value through load flow calculation and objective function of each particle until reaching maximum iteration.

(8) Output optimal allocation and finish the optimization.

\subsection{Flow Diagram of Optimal Solution}

The flow diagram of IPSO algorithm for solving DG optimization problems is as follows:

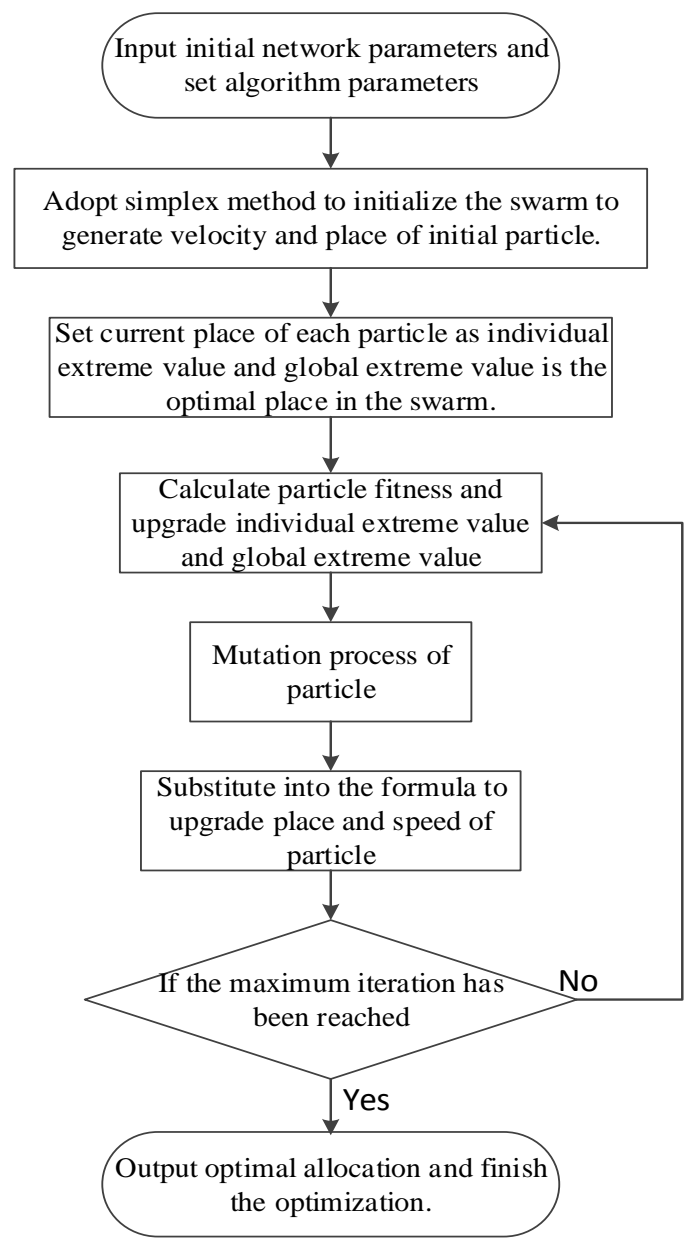

Figure 1. Flow Chart of IPSO Algorithm for Solving DG Optimization Problems 


\section{Analysis of Examples}

A 29-node micro grid network structure is taken as an example as shown in Figure 2. It is assumed that voltage level of network bus is $10 \mathrm{kV}$ and gross active loads of the micro grid before placement of DGs is $9.7 \mathrm{MW}$ and total reactive load is $6.2 \mathrm{kVar}$. Annual maximum generating hours of distributed generation is $3000 \mathrm{~h}$. In the example, it is assumed that payback period of investment is 10 years. Set dimension of particle swarm algorithm $D=10$, swarm scale is 200 , mutation rate $P_{m}=0.3$, iteration number is 20 .

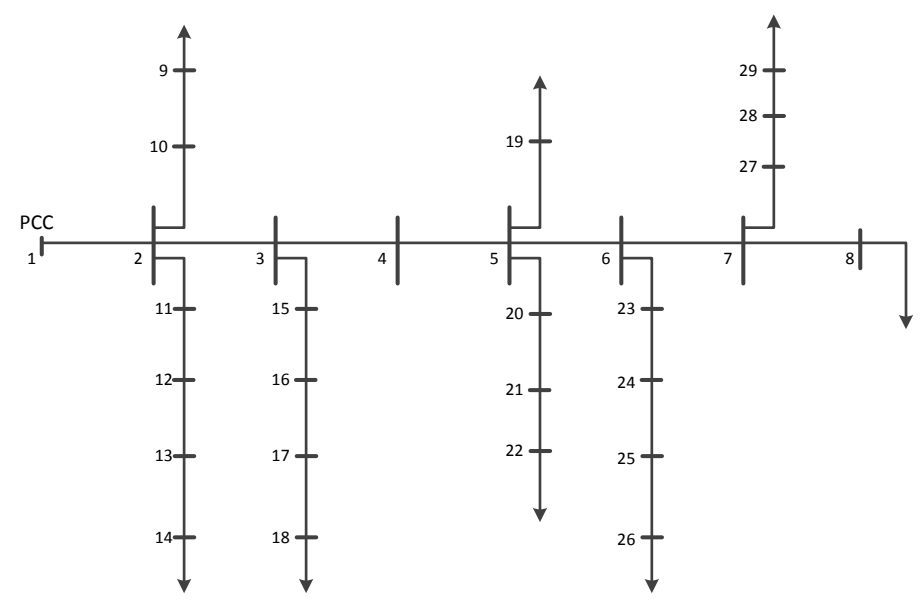

Figure 2. A 29-Node Micro Grid Network Structure

According to the correlation principle of place of distributed generation, after geographical environment, wind power and sunlight intensity in the region where micro grid network structure is constructed are investigated, three types of DGs including wind power generator, PV power system and micro gas turbine are considered. The investment and operating and maintenance cost of these three types of DGs are listed in the following table.

Table 2. Costs of Candidate DG

\begin{tabular}{cccc}
\hline & $\begin{array}{c}\text { Wind power } \\
\text { generation }\end{array}$ & $\begin{array}{c}\text { PV power } \\
\text { generation }\end{array}$ & $\begin{array}{c}\text { Micro gas } \\
\text { turbine }\end{array}$ \\
\hline $\begin{array}{c}\text { Investment cost } \\
\text { (Yuan/kW) }\end{array}$ & 8000 & 12000 & 6000 \\
\hline $\begin{array}{c}\text { Maintenance cost } \\
\text { (Yuan/kWh) }\end{array}$ & 0.3 & 0.2 & 0.1 \\
\hline
\end{tabular}

The installation location of distributed generation is determined according to location selection principle. Therefore, economic optimization principle is regarded as the objective to carry out placement optimization on 5 important load nodes in this network. Through repeated debugging and solution with IPSO algorithm, the optimal scheme for placement of DG is determined and the placement and capacity are shown in Table 3: 
Table 3. Installation Place and Capacity of Distributed Generations

\begin{tabular}{ccc}
\hline $\begin{array}{c}\text { DC placement } \\
\text { nodes }\end{array}$ & Capacity & Types \\
\hline 4 & $16 \times 100$ & Micro gas turbine \\
\hline 7 & $20 \times 100$ & PV \\
\hline 12 & $24 \times 100$ & Micro gas turbine \\
\hline 18 & $20 \times 100$ & Wind power \\
\hline 28 & $20 \times 100$ & Wind power \\
\hline
\end{tabular}

Then the comprehensive operation status of the micro grid optimized with placement of distributed generation and micro grid without distributed generation are compared and analyzed in the following Table 4:

Table 4. Micro-Grid Operation Status

\begin{tabular}{ccc}
\hline Schemes & $\begin{array}{c}\text { Scheme I (micro } \\
\text { grid connected } \\
\text { with DG) }\end{array}$ & $\begin{array}{c}\text { Scheme II } \\
\text { (micro grid } \\
\text { without DG) }\end{array}$ \\
\hline $\begin{array}{c}\text { DG investment cost } \\
(10,000 \text { Yuan) }\end{array}$ & 858.52 & - \\
\hline $\begin{array}{c}\text { DG operating and } \\
\text { maintenance cost } \\
(10,000 \text { Yuan) }\end{array}$ & 1203.36 & - \\
\hline $\begin{array}{c}\text { Cost for network loss of } \\
\text { comprehensive } \\
\text { operation (10,000 Yuan) }\end{array}$ & 92.13 & 52.03 \\
\hline $\begin{array}{c}\text { Power interruption loss } \\
\text { cost (10,000 Yuan) }\end{array}$ & 14.4 & 31.4 \\
\hline $\begin{array}{c}\text { Power purchase cost } \\
(10,000 \text { Yuan) }\end{array}$ & -703.97 & 1782 \\
\hline $\begin{array}{c}\text { Gross cost (10,000 } \\
\text { Yuan) }\end{array}$ & 1466.48 & 1865.43 \\
\hline
\end{tabular}

Through comparative analysis in Table 4, we can find that total operation cost of micro grid without distributed generation is 18.6843 million Yuan. The economy of micro grid optimized with placement of distributed generation is superior to micro grid without distributed generation.

In Scheme I, after DG is placed in micro grid, the investment and operation cost of DG accounts for $80 \%$ of total operation cost and mainly includes construction cost of wind power and PV as well as fuel cost of micro gas turbine. The power purchase charge in scheme I is negative, showing that DG makes great contributions in micro grid and is able to supply powers to superior main grid when the power demands of its own loads have been satisfied and meanwhile the possibility of loss caused by power interruption in micro grid is reduced and reliability of micro grid is improved greatly. But PV power generation and wind power generation are random and undulatory and excessive placement will impact stability of micro grid, therefore the optimization result indicates that it is essential to limit the capacity of $\mathrm{PV}$ and wind generation in micro grid.

Although construction cost, operating and maintenance cost and fuel fee of DGs are high, power purchase benefits can be obtained from large grid and environment subsidy for use of renewable energy sources will be given from the government, so the micro grid with DGs will create better economic benefits according to comprehensive operating charge and benefit of environmental protection during operating of micro grid with DGs. 
Thus we can see that reasonable placement and capacity of distributed generation will greatly improve economy of DGs. Different types of DGs will pose significant impact on reliability of micro grids. At the same time, with progress of science and technology and development and application of renewable energy sources, the construction cost of DGs will be lower and lower and the economic benefits caused by DGs will be more and more significant.

\section{Comparison of Optimization Performance between IPSO and PSO}

Take operation cost of micro grids as the objective function and respectively use PSO and IPSO algorithm for optimizing solution. Fitness curves of these two algorithms during optimizing process are shown in Figure 3.

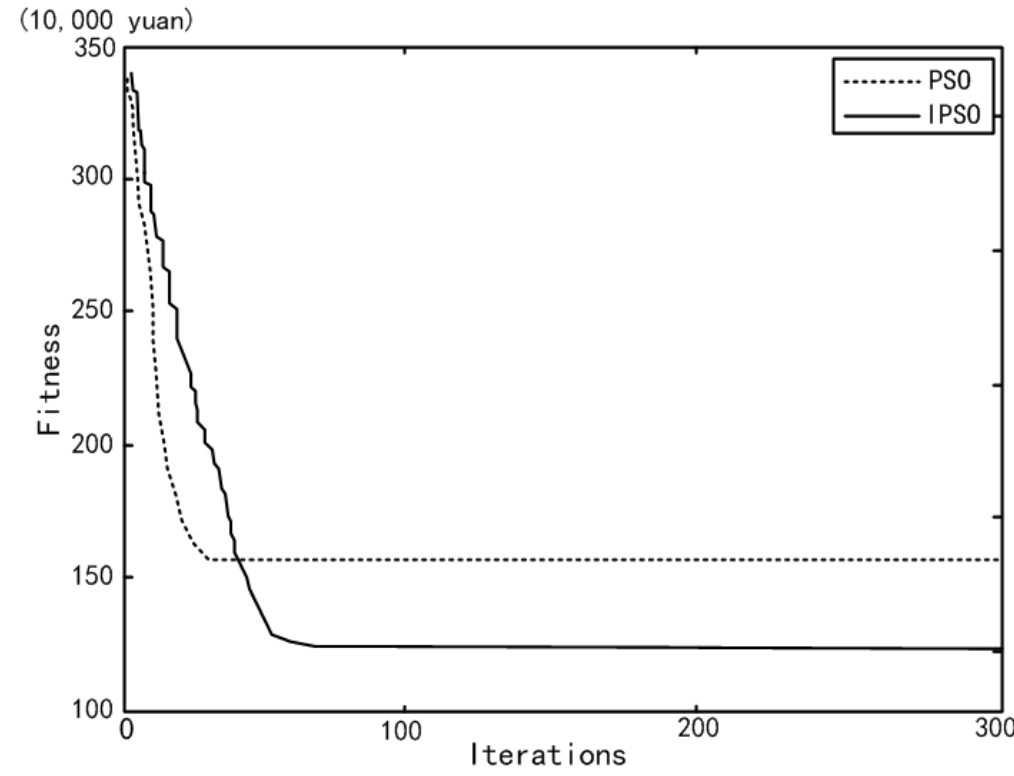

Figure 3. Comparison of Optimization Performance between IPSO and PSO

Figure 3, shows that in the iterative process, PSO algorithm enters local optimization from rapid convergence at the beginning and stops the searching, but IPSO algorithm shows better global search capability and can jump out local optimization process for multiple times and finally obtains a better integral optimal solution. Thus IPSO algorithm researched in this paper is more effective during solving operation cost and optimizing objective convergence and owns high searching efficiency and calculation accuracy.

\section{Conclusion}

In this paper, according to load importance and the access correlation of different types of distributed generation, a multi-objective economic model based on the fixed location of the distributed generation is established to minimize the micro grid loss and operation cost. The improved PSO (IPSO) algorithm initializes the PSO algorithm with simplex method. The average extreme value and mutation operators are introduced to improve the convergence ability, searching efficiency and the calculation accuracy. Compared with PSO algorithm, IPOS proposed in this paper has better performance in solving operation cost problem of micro grid. Through analysis on a 29 -node micro grid network structure, IPSO algorithm is adopted to obtain the optimal planning result of DGs in micro grid. The optimal result shows 
that the access of DGs can improve economy and reliability of micro grids. and different access ways and types of DGs will have different impacts on the micro grid. It proves the efficiency and correctness of the model and algorithm proposed in this paper.

\section{Acknowledgements}

The research work was supported by National High Technology Research and Development Program of China 863 Program (2014AA052003), and International S\&T Cooperation Program of China (2013DFG71630).

\section{References}

[1] Y. Jianxin, S. Jian, LV Zhipeng, "Overview on Micro-grid Technology[J]”, .Proceedings of the CSEE, vol. 34, no. 1, (2014), pp. 57-70.

[2] Z. Limei, T. Wei, Z. Yunjun, "Analysis of DG influences on system voltage and losses in distribution network[J]", Power System Protection and Control, vol. 39, no. 5, (2011), pp. 91-96.

[3] L. Caihao, D. Xianzhong, "Distributed generation and its impact on power system[J]", Automation of Electric Power Systems, vol. 25, no. 12, (2001), pp. 53-56.

[4] Q. Xiaoyan, X. Lili, L. Xingyuan, "Planning of Distributed Generation in Construction of Smart Grid [J]", Power System Technology, vol. 34, no. 4, (2010), pp. 7-10.

[5] W. Chengshan, C. Kai, X. Yinghua. "Siting and Sizing of Distributed Generation in Distribution Network Expansion Hanning[J]", Automation of Electric Power Systems, vol. 30, no. 3, (2006), pp. 38-43.

[6] L. Bo, Z. Yan, Y. Na, "Improved Particle Swarm Optimization Method and Its Application in the Siting and Sizing of Distributed Generation Planning [J]", Transactions of China Electrotechnical Society, vol. 23, no. 2, (2008), pp. 103-108.

[7] M. Gandomkar, M. Vakilian, M. Ehsan, "A combination of genetic algorithm and simulated annealing for optimal DG allocation in distribution networks [J]", CCECE/CCGEI, Saskatoon, (2005), pp. 645648.

[8] H. Falaghi, M. Haghifam, "ACO based algorithm for distributed generation sources allocation and sizing in distribution systems [C]", //Power Tech, 2007 IEEE Lausanne.IEEE, (2007), pp. 555-560.

[9] Z. Limei, T. Wei, Z.Yunjun, et a1., "The integrated evaluation of impact of distributed generation on distribution network [J]", Power System Protection and Control, vol. 38, no. 21, (2010), pp. 132-136.

[10] Y. Qi, M. Shiying, S. Yunting, "Comprehensive Evaluation of Distributed Generation Planning Scheme[J]”, Power System Technology, vol. 36, no. 2, (2012), pp. 212-216.

[11] Z. Limei, T. Wei, "Back/Forward Sweep Power Flow Calculation Method of Distribution Networks With DGs [J]”, Transactions of China Electrotechnical Society, vol. 25, no. 8, (2010), pp. 123-130.

[12] Z. Jingjing, L. Xin, X. Zhong, "Calculation of three-phase unbalanced power flow in distribution network containing distributed generation [J]", Power System Technology, vol. 33, no. 3, (2009), pp. 94-98(in Chinese).

[13] L. Jia, L. Dan, G. Liqun, "Vector Evaluated Adaptive Particle Swarm Optimization Algorithm for Multi-objective Reactive Power Optimization [J]", Proceedings of the CSEE, vol. 28, no. 31, (2008), pp. 22-28.

[14] W. Xingwang, Q. Xiaoyan, "Distributed generation planning in distribution system based on modified particle swarm optimization algorithm [J]", Power System Protection and Control, vol. 37, no. 14, (2009), pp. 16-20.

[15] S. Jinrong, L. Bingyi, W. Xiaokai, "Particle swarm optimization using average information of swarm [J]", Computer Engineering and Applications, vol. 43, no. 10, (2007), pp. 58-59.

\section{Authors}

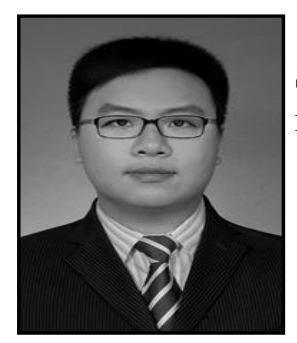

Pinzhuo Zeng, he is currently pursuing the Master Degree in SEIEE from Shanghai Jiao Tong University. His research interests include power system analysis, and Microgrid. 
Keyou Wang. he received the B.S. and M.S. degrees in electrical engineering from Shanghai Jiaotong University, Shanghai, China, in 2001 and 2004, respectively, and the Ph.D. degree from the Missouri University of Science \& Technology (formerly University of Missouri-Rolla) in 2008. He is currently an associate professor of Shanghai Jiaotong University. His research interests include power system dynamics and stability, FACTS and renewable energy integration.

Guojie Li. he received his B.E. and M.E. degrees in Electrical Engineering from Tsinghua Univercity, Beijing, China in 1989 and 1993, respectively. He also received $\mathrm{Ph}$. D degree in the School of EEE, Nanyang Technological University Singapore in 1999. He is now a professor in the Dept. of Electrical Engineering, Shanghai Jiaotong University, Shanghai, China. His current research interests include power system analysis and control, wind and PV power control and integration, and Microgrid.

Xiuchen Jiang. he is a professor in the Dept. of Electrical Engineering, Shanghai Jiaotong University, Shanghai, China. His current research interests include smart grid and high voltage technique. 